\title{
Transcriptional Profile of Kidney from Type 2 Diabetic db/db Mice
}

\author{
Haojun Zhang, ${ }^{1}$ Tingting Zhao, ${ }^{1}$ Zhiguo Li, $^{2}$ Meihua Yan, ${ }^{1}$ Hailing Zhao, ${ }^{1}$ \\ Bin Zhu, ${ }^{1}$ and Ping $\mathrm{Li}^{1}$ \\ ${ }^{1}$ Beijing Key Lab Immune-Mediated Inflammatory Diseases, Institute of Clinical Medical Sciences, \\ China-Japan Friendship Hospital, Beijing, China \\ ${ }^{2}$ Department of Medical Research Center, International Science and Technology Cooperation Base of Geriatric Medicine, \\ North China University of Science and Technology, Tangshan, China \\ Correspondence should be addressed to Ping Li; lp8675@163.com
}

Received 30 September 2016; Accepted 7 December 2016; Published 23 January 2017

Academic Editor: Shuta Ishibe

Copyright (C) 2017 Haojun Zhang et al. This is an open access article distributed under the Creative Commons Attribution License, which permits unrestricted use, distribution, and reproduction in any medium, provided the original work is properly cited.

\begin{abstract}
Diabetic nephropathy (DN), a common diabetic microvascular complication, is characterized by progressive glomerular sclerosis and tubulointerstitial fibrosis. However, the underlying mechanisms involved in DN remain to be elucidated. We explored changes in the transcriptional profile in spontaneous type 2 diabetic $\mathrm{db} / \mathrm{db}$ mice by using the cDNA microarray. Compared with control $\mathrm{db} / \mathrm{m}$ mice, the $\mathrm{db} / \mathrm{db}$ mice exhibited marked increases in body weight, kidney weight, and urinary albumin excretion. Renal histological analysis revealed mesangial expansion and thickness of the basement membrane in the kidney of the $\mathrm{db} / \mathrm{db}$ mice. A total of 355 differentially expressed genes (DEGs) were identified by microarray analysis. Pathway enrichment analysis suggested that biological oxidation, bile acid metabolism, and steroid hormone synthesis were the 3 major significant pathways. The top 10 hub genes were selected from the constructed PPI network of DEGs, including Ccnb2 and NrIi2, which remained largely unclear in DN. We believe that our study can help elucidate the molecular mechanisms underlying DN.
\end{abstract}

\section{Introduction}

With the increasing prevalence of diabetes worldwide, diabetic nephropathy, a serious and major microvascular complication of diabetes mellitus (DM), has also become a global problem affecting about $40 \%$ of patients with diabetes and is the primary cause of end-stage renal diseases (ESRD) in developed countries $[1,2]$. DN is characterized by excessive accumulation of extracellular matrix (ECM) with thickening of glomerular and tubular basement membranes and increased mesangial materials [3]. Therapies for DN remain clinically limited thus far [4]. Although attempts including intensive control of hyperglycemia and hypertension reduced albuminuria accompanied with delay in DN progression, many patients still experience exacerbated renal injuries and develop ESRD [2]. A better understanding of the molecular mechanisms of DN can thus help establish effective therapeutic strategies for the condition.
To fundamentally understand and elucidate the mechanism of DN, high-throughput microarrays could be used to investigate the underlying genetic characteristic of processes involved in DN. These techniques have been widely used in screening the potential targets for DN. Distinct patterns of molecules and pathways between glomeruli and tubulointerstitial compartment were identified by transcriptome analysis of human DN [5]. The transcriptional profile from renal biopsies revealed activation of the NF-kB pathway in DN [6]. Watanabe et al. indicated that the macrophage migration inhibitory factor could be an important cytokine for induction of microalbuminuria by the cDNA microarray [7]. Thus, microarray analysis can effectively identify key molecular events and pathways involved in DN.

Animal models exhibit a remarkable advantage when difficulties arise in clinical trials. $\mathrm{Db} / \mathrm{db}$ mice were considered good animal models for DN. The G-to-T point mutation of leptin receptor mutation (LepRdb/db) from $\mathrm{db} / \mathrm{db}$ mice 
results in defective responses to leptin, leading to the development of hyperphagia, obesity, hyperlipidemia, hyperinsulinemia, insulin resistance, and diabetes. $\mathrm{Db} / \mathrm{db}$ mice could develop mild kidney damage, which is similar to early-stage of human type $2 \mathrm{DN}$. Thus, $\mathrm{db} / \mathrm{db}$ mice are commonly used to investigate the mechanisms of renal injury associated with type 2 diabetes [8].

In the current study, we employed global microarray analysis combined with bioinformatics to explore the differential gene expression in $\mathrm{db} / \mathrm{db}$ and $\mathrm{db} / \mathrm{m}$ mice in order to identify candidate genes that may be involved in the development of DN.

\section{Materials and Methods}

2.1. Animal Experimentation. Male $\mathrm{db} / \mathrm{db}$ mice $(n=6)$ at 10 weeks old and their nondiabetic $\mathrm{db} / \mathrm{m}$ littermates $(n=6)$ were purchased from Beijing Vital River Laboratory Animal Co. Ltd. (Beijing, China). Animals were given free access to standard chow and water for 12 weeks. At the end of the experiment, all mice were weighed, and individual $24 \mathrm{~h}$ urine collections were obtained using metabolic cages. Subsequently, all animals were sacrificed at 22 weeks of age. Their blood was collected, and their kidneys were harvested, weighed, and immediately frozen in liquid nitrogen for further analysis. The mice were housed in an animal care facility at China-Japan Friendship Hospital. The protocol was approved by the ethics committee of the Institute of Clinical Medical Sciences at China-Japan Friendship Hospital and then executed as specified in the National Institutes of Health Guide for the Care and Use of Laboratory Animals.

2.2. Urinary Albumin Excretion and Renal Histology. Urinary albumin concentrations were determined using Mouse Albumin ELISA Quantitation Set (Bethyl Laboratories Inc., Montgomery, TX) in accordance with the manufacturer's instructions.

Dissected kidney samples were fixed in buffered formalin (10\%) for $24 \mathrm{~h}$, dehydrated, embedded in paraffin, sectioned at $3 \mu \mathrm{m}$ thickness, and mounted on slides. The paraffin sections were stained with periodic acid-Schiff (PAS) and examined under light microscopy.

\subsection{RNA Extraction, Amplification, Labeling, and Hybridiza-} tion. Renal cortices were carefully isolated from 3 mice in $\mathrm{db} / \mathrm{db}$ and $\mathrm{db} / \mathrm{m}$ group, respectively, for microarray analysis. Total RNA were extracted using TriZol Reagent (Invitrogen, Carlsbad, CA) in accordance with the manufacturer's instructions. Removal of contaminating genomic DNA was conducted using DNase I digested for $15 \mathrm{~min}$ at $37^{\circ} \mathrm{C}$. After being cleaned up with RNeasy Kit (Qiagen, Hilden, Germany), the RNA quantities and qualities were determined by spectrophotometry and $1 \%$ formaldehyde denaturing gel electrophoresis, respectively. Samples with bright bands of ribosomal $28 \mathrm{~S}$ to $18 \mathrm{~S}$ RNAs in a ratio $>1.5$ : 1 were used for microarray analysis.

Microarray experiments were performed by CapitalBio Corporation (Beijing, China), a service provider authorized by Affymetrix, Inc. (Santa Clara, CA) in accordance with the Affymetrix GeneChip ${ }^{\circledR}$ manual. As much as $100 \mathrm{ng}$ of total RNA was used for cDNA synthesis. Biotin-tagged cRNA was produced using the GeneChip IVT Labeling Kit (Affymetrix). Subsequently, $15 \mu \mathrm{g}$ fragmented cRNA, with Control Oligo B2 and eukaryotic hybridization controls (bioB, bioC, bioD, cre), was hybridized to the Affymetrix Mouse Genome 430 2.0 Array (Affymetrix, Santa Clara, CA) at $45^{\circ} \mathrm{C}$ for $16 \mathrm{~h}$ (Affymetrix GeneChip Hybridization Oven 640). After hybridization, the GeneChip arrays were washed and then stained with streptavidin phycoerythrinonan with Affymetrix GeneChip Fluidics Station 450, followed by scanning with Affymetrix GeneChip Scanner 3000 7G.

Data were analyzed using Affymetrix Expression Console and Transcriptome Analysis Console (TAC) software. The gene array was run in triplicate, and the significance of the difference for each gene was determined by one-way ANOVA. Differentially regulated genes (DEGs) were defined as genes with a 1.5-fold and greater change over controls with $p<0.05$. These microarray data have been submitted to the Gene Expression Omnibus repository and are accessible through accession number GSE87359.

2.4. Enrichment Analysis for GO and Pathway. The software ClueGO 2.0.6 for "Cytoscape 3.0.1" was used to apply the "Function" analysis mode and the "Compare" cluster analysis type (cluster 1 = upregulated genes and cluster $2=$ downregulated genes). The statistical test used for the enrichment was based on a two-sided hypergeometric option with the Bonferroni correction, a $p$ value less than 0.05 , and a kappa score of 0.40. The pathway databases included KEGG, Reactome, and Wiki Pathways. The Gene Ontology (GO) databases included the biological process and molecular function Gene Ontology, updated to 10.09.2013. The Benjamini-Hochberg false discovery rate was set to 0.05 .

2.5. Construction of PPI Network. The PPI network of DEGs in each group was constructed in the Search Tool for the Retrieval of Interacting Genes (STRING) database using Cytoscape 2.8, a free software package for visualizing, modeling, and analyzing the integration of biomolecular interaction networks with high-throughput expression data and other molecular states. The interactive pattern degree was set at 0.4 .

2.6. Validation of DEGs by Quantitative PCR ( $q P C R)$. The expression levels of 14 DEGs (highly upregulated or downregulated in $\mathrm{db} / \mathrm{db}$ mice) were measured by $\mathrm{qPCR}$ in triplicate for the technical validation of microarray data. Results were expressed as fold expression relative to the expression in the control group by using the delta-delta $\mathrm{Ct}(\Delta \Delta \mathrm{Ct})$ method. The level of $\beta$-actin RNA was used as an internal standard. All of these primers are listed in Table 1.

2.7. Statistical Analysis. Data are presented as means \pm SEM and compared using Student's $t$-test. $p<0.05$ was considered statistically significant. 
TABLE 1: Primers used in qPCR.

\begin{tabular}{|c|c|c|}
\hline & Forward & Reverse \\
\hline$A b c c 3$ & CCATTGACTTGGAGACGGATG & CGCAATGAGGTTGACTGGAG \\
\hline Apoh & TGCATGGCGACAAAATTCAC & CCGTTTTCCAGAAAGCCAGAG \\
\hline Ccnb2 & TTGCCTGTCTCAGAAGGTGC & GGGGAGGCCAGGTCTTTGATG \\
\hline Сур 2j13 & CCACCCCAGACATCTTCAAT & AATTGTTCTCCGAGGCAAGCT \\
\hline Cyp27b1 & ACCCATTTGCATCTCTTCCСТT & CGGGTCATGGGCTTGATAGG \\
\hline Esr1 & CGTTTCTGTCCAGCACCTTG & CATGTGCCGGATATGGGAAAG \\
\hline Gc & GGACAAAAACACCCAACACCT & CCATCTCTGTGGTGCTTGATT \\
\hline Maob & ACTGAAACAGCCTCACACTGG & GGTACTGGTAATGGGTCGTGC \\
\hline Nrli2 & TCGAAGACCCTAATGGTGGC & GAGCAGGATATGGCCGACTAC \\
\hline Slc7a13 & TGTTTTGTGCCCTGAATGTCC & CCCAACGCTATGAATGTGAAC \\
\hline Slcola1 & TTCCGGCACCTGTTTACTTTG & TAGAATGAAGACTGCGGGGAG \\
\hline Ugt2b37 & TCCTTTGTTTGGAGAACAGCAT & AGGCTGGTCATGGTGAATGG \\
\hline Hsd17b2 & AATCATCAGACAGGAGCTTGAC & ССТСTCTTTCAAGGTCGGGAT \\
\hline Сур7b1 & GTATTATATTCTTCGGCATCCTG & CATATCCTCCTGCACTTCTCG \\
\hline$\beta$-actin & ACCCTAAGGCCAACCGTGAAAAG & CATGAGGTAGTCTGTCAGGT \\
\hline
\end{tabular}

\section{Results}

3.1. Manifestation of Type $2 \mathrm{DN}$ from $\mathrm{db} / \mathrm{db}$ Mice. As shown in Figure 1, body weight and blood glucose in $\mathrm{db} / \mathrm{db}$ mice were markedly higher than those in $\mathrm{db} / \mathrm{m}$ mice. Compared with those of the control $\mathrm{db} / \mathrm{m}$ mice, significant increases in $24 \mathrm{~h}$ urinary albumin and kidney weight were indicated in the $\mathrm{db} / \mathrm{db}$ mice. Histological examination demonstrated a mild accumulation of mesangial matrix. Thickening of the glomerular base membrane was observed in $\mathrm{db} / \mathrm{db}$ mice. No remarkable changes in the tubulointerstitium were observed in the model.

3.2. Identification of Differentiated Genes (DEGs). In the study, a cutoff of 1.5-fold change or greater was used to selectively analyze genes that were altered by a significantly higher margin compared with normal controls. After filtering, we found that 164 genes were downregulated and 191 genes were upregulated in the $\mathrm{db} / \mathrm{db}$ mice. Figure $2(\mathrm{a})$ shows a heat map distribution of those DEGs. The genes shown in red indicate a high signal, whereas those in green indicate a low signal. The heat map demonstrated that several areas with highly altered (upregulated or downregulated) signals were shown in $\mathrm{db} / \mathrm{db}$ mice compared with $\mathrm{db} / \mathrm{m}$ mice. All analyses were performed using Transcriptome Analysis Console (Affymetrix). The genes were evenly distributed among the chromosomes, with no significant clustering on any one chromosome, which could suggest site-specific gene induction (Figure 2(b)). These genes are represented as a scatter plot (Figure 2(c)) showing the upregulated genes in red and the downregulated genes in green. These DEGs were plotted against significance (Figure $2(\mathrm{~d})$ ), with the red dots in Figure 2(c) denoting significantly induced genes and the green dots in Figure 2(c) denoting significantly repressed genes. These figures show that the gene expression profile in $\mathrm{db} / \mathrm{db}$ markedly differs from that in $\mathrm{db} / \mathrm{m}$ mice.
3.3. GO Term Enrichment Analysis of DEGs. Using the Cytoscape plug-in ClueGO, we performed Gene Ontology enrichment analysis to focus on the GO categories and thus understand the biological functions associated with $\mathrm{DN}$. In general, 232 GO terms were significantly enriched, as shown in Figure 3(a). The top 10 most significant GO terms are listed in Table 2 by their $p$ values. These GO terms were categorized into 29 subgroups. Specifically, the downregulated genes were mainly related to regulation of lipid metabolic process, regulation of platelet cell cycle, ATPase activity, and nucleoside-triphosphatase activity (Figure 3(b)). Meanwhile, the upregulated genes were related to kinase activity, transcription factor activity, and response to reactive oxygen species (Figure 3(c)).

3.4. Pathway Enrichment Analysis of DEGs. Furthermore, in the pathway enrichment analysis, 41 pathway terms were significantly enriched, as shown in Figure 4(a). The top 10 most significant pathway terms are listed in Table 3 by the $p$ value. These pathway terms have been categorized into 18 subgroups. Specifically, the downregulated genes were mainly related to regulation of lipid metabolic process, regulation of platelet cell cycle, ATPase activity, and nucleosidetriphosphatase activity (Figure 4(b)). Meanwhile, the upregulated genes were related to kinase activity, transcription factor activity, and response to reactive oxygen species (Figure 4(c)).

3.5. PPI Network and Subnetwork of DEGs. According to the PPI dataset downloaded from STRING, the PPI network consisted of 166 gene signatures and 411 interactions based on 355 DEGs. The network was binary, and all interactions were unweighted and undirected. The giant component, which included the majority of the entire network genes containing 143 nodes and 395 edges, was constructed (Figure 5 ). The top 10 genes in degree and betweenness centrality (BC) are listed in Table 4. 


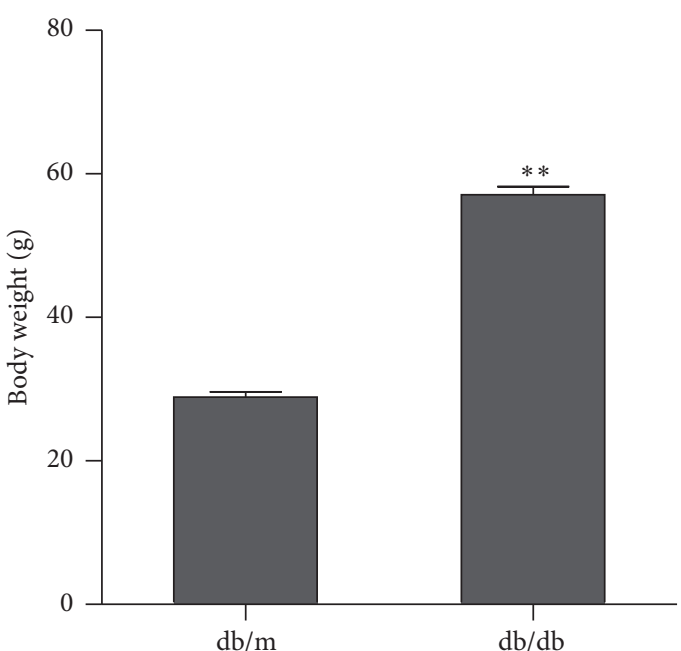

(a)

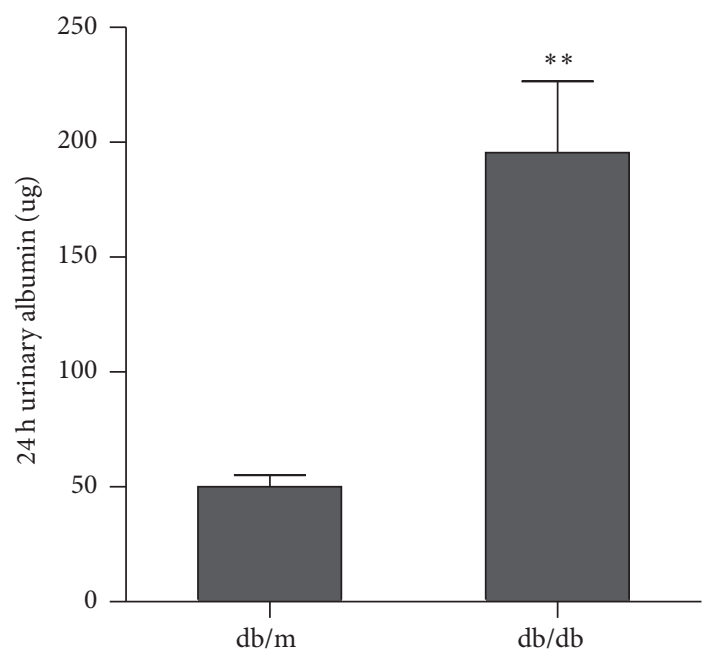

(c)

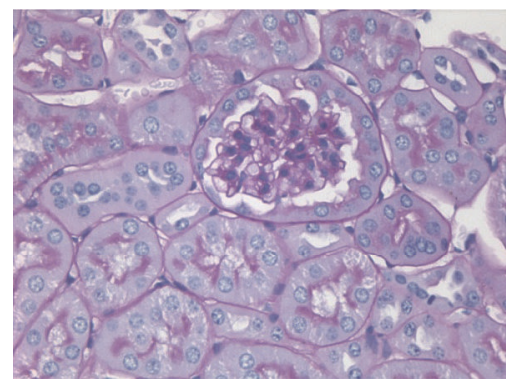

$\mathrm{db} / \mathrm{m}$

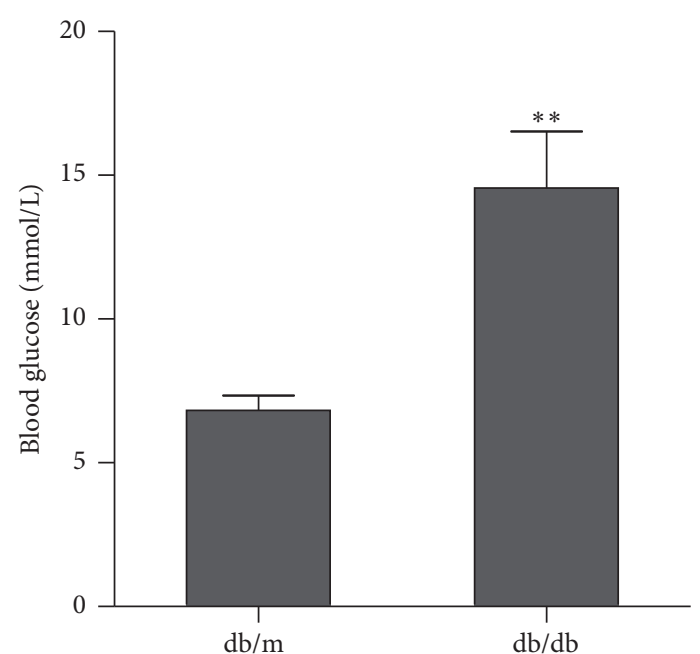

(b)

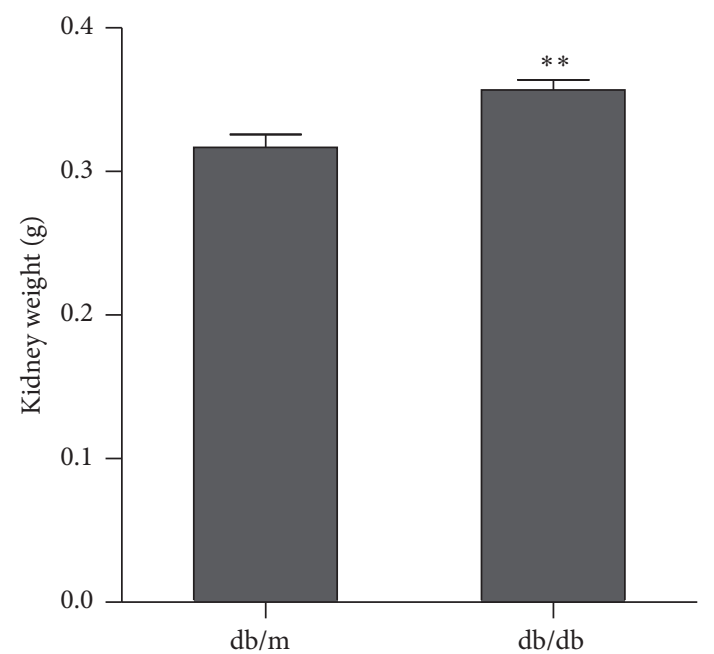

(d)

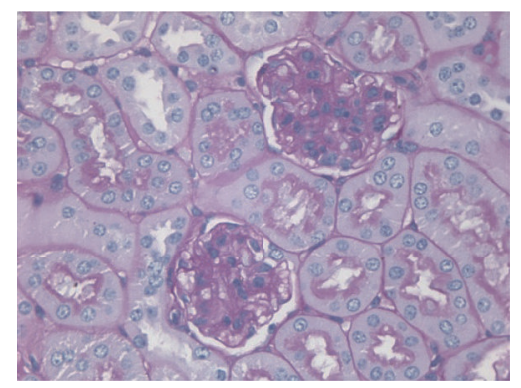

$\mathrm{db} / \mathrm{db}$

(e)

FIGURE 1: Comparison between $\mathrm{db} / \mathrm{db}$ mice and $\mathrm{db} / \mathrm{m}$ mice in terms of body weight (a), blood glucose (b), $24 \mathrm{~h}$ urinary albumin (c), and kidney weight (d). Renal histological changes are denoted by (e). Data presented as mean $+\mathrm{SEM}^{* *} p<0.01, \mathrm{db} / \mathrm{db}$ versus $\mathrm{db} / \mathrm{m}$.

3.6. Confirmation with $q P C R$. To validate the microarray results, we analyzed the mRNA levels of representative genes by using qPCR. As shown in Figure 6, the relative mRNA levels of $A b c c 3, C c n b 2, C y p 27 b 1, G c, M a o b$, and Nr1i2 in db/db mice were significantly higher, whereas the mRNA levels of Apoh, Cyp2j13, Esr-1, Cyp7b1, Hsd17b2, Slc7a13, Slcola1, and Ugt2b37 were lower compared with those in $\mathrm{db} / \mathrm{m}$ mice (all $p<0.05$ ). These outcomes were consistent with the microarray results.

\section{Discussion}

DN has been a widely known issue in public health because of the lack of available curative methods. The pathogenesis 


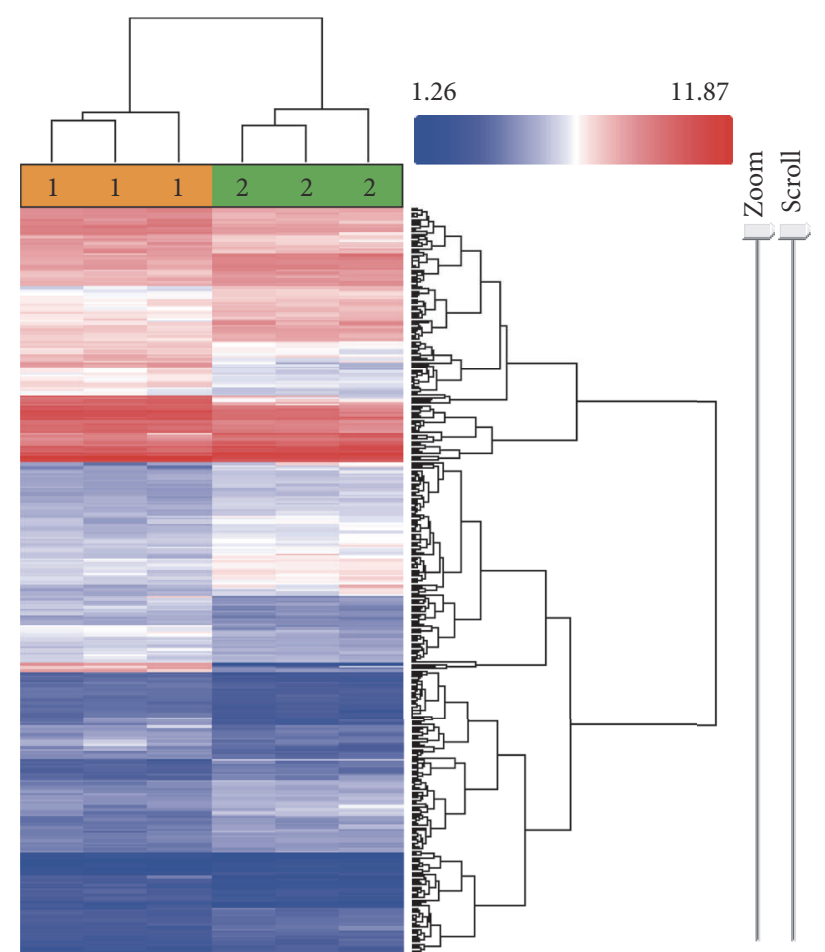

(a)

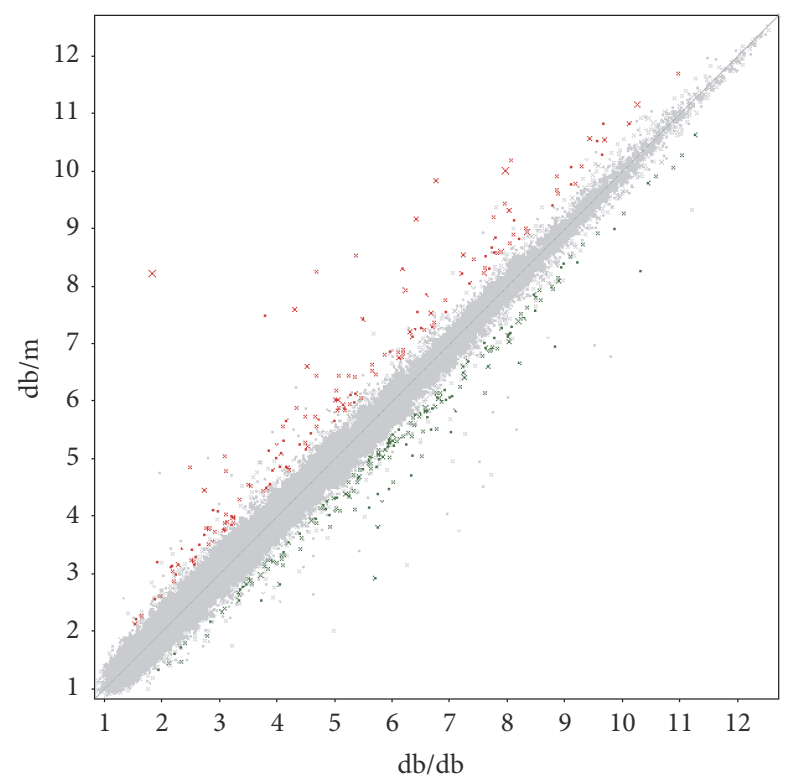

(c)

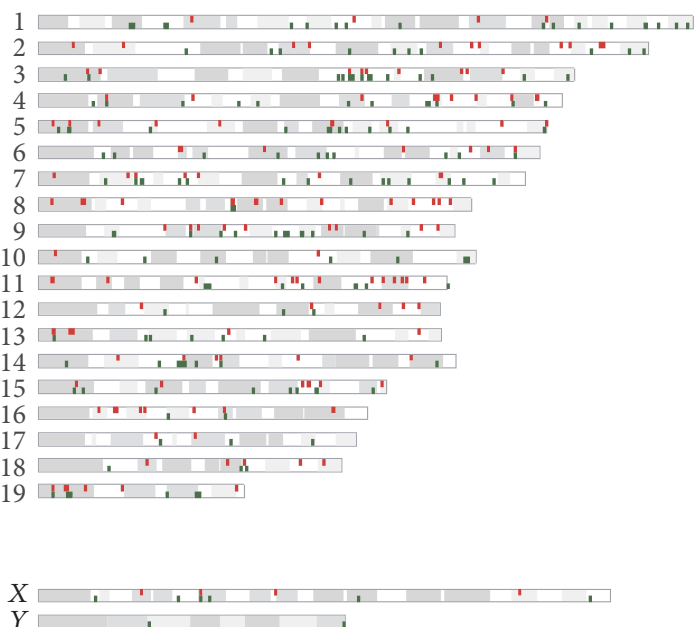

(b)

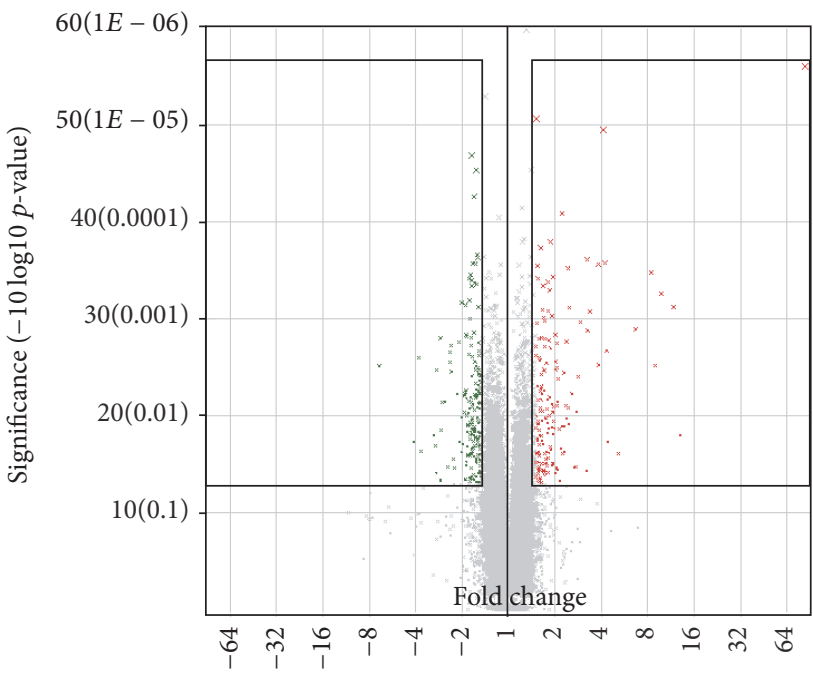

(d)

FIGURE 2: Identification of DEGs in the transcriptional profile from $\mathrm{db} / \mathrm{db}$ and $\mathrm{db} / \mathrm{m}$ mice at $22 \mathrm{w}$ old. (a) Signal values are plotted and clustered in a heat map to determine overt differences in the signal between the 2 samples by TAC. (b) Chromosome distribution analysis shows where induced or repressed genes in $\mathrm{db} / \mathrm{db}$ mice are located in the mouse genome. (c) Fold change calculated using the TAC software is exhibited as a scatter plot. Genes upregulated in $\mathrm{db} / \mathrm{db}$ mice are shown in red, whereas downregulated genes are shown in green. (d) A fold change for each gene exceeding 1.5-fold change is plotted against significance as calculated by one-way ANOVA in a volcano plot. DEGs within the black boxes are considered for further ontology and pathway analysis. 


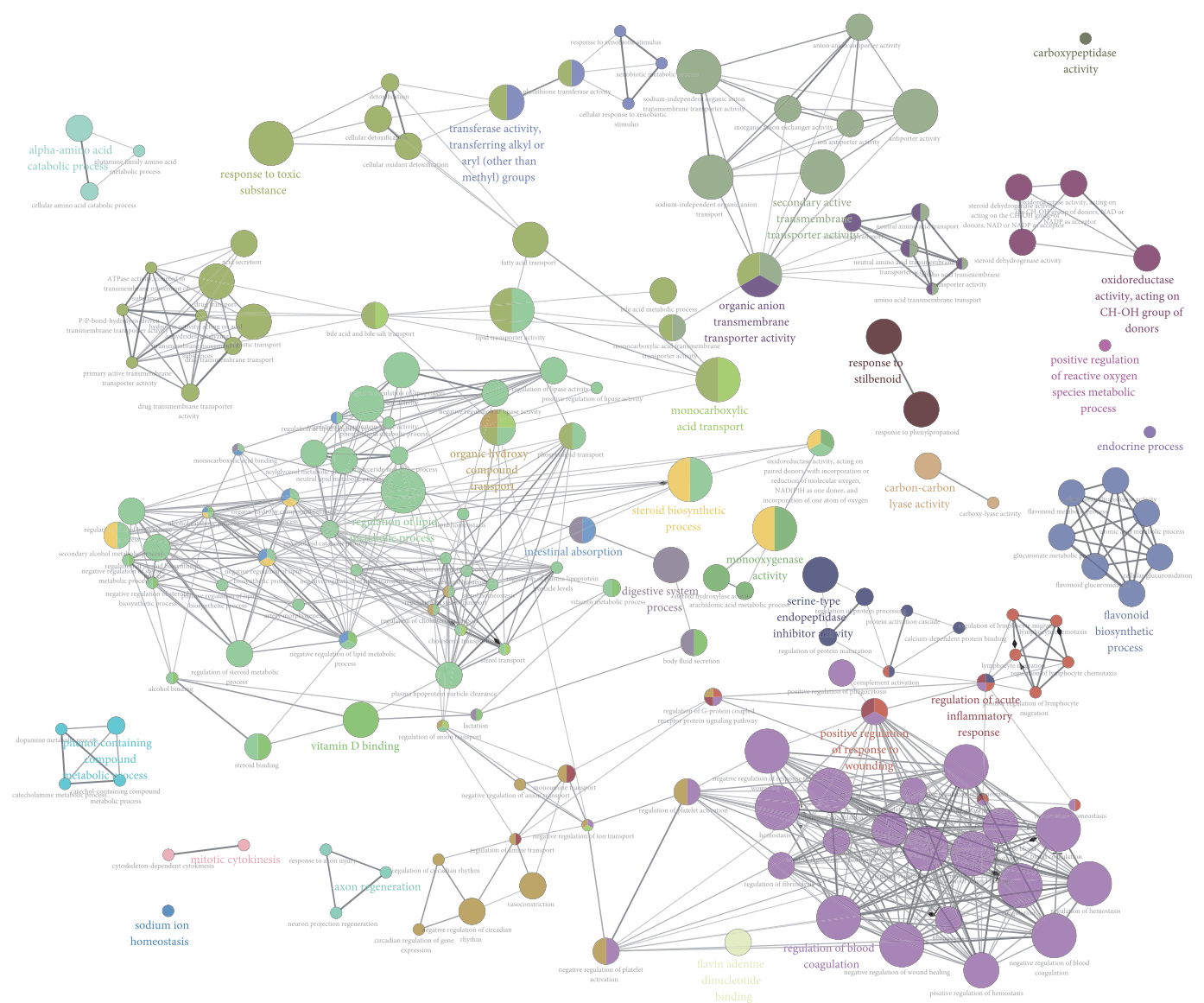

(a)

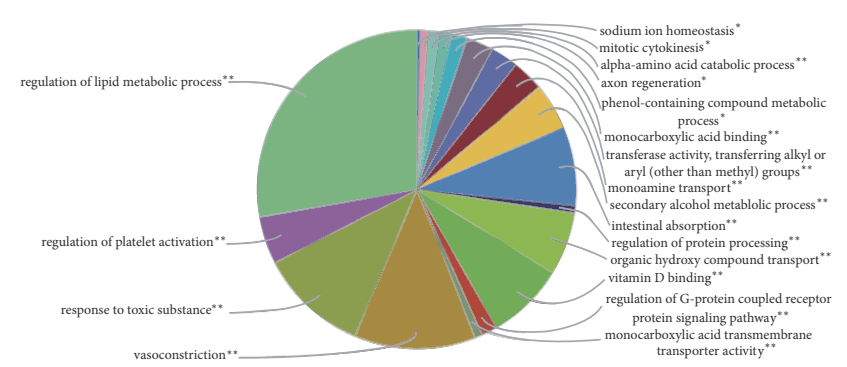

(b)

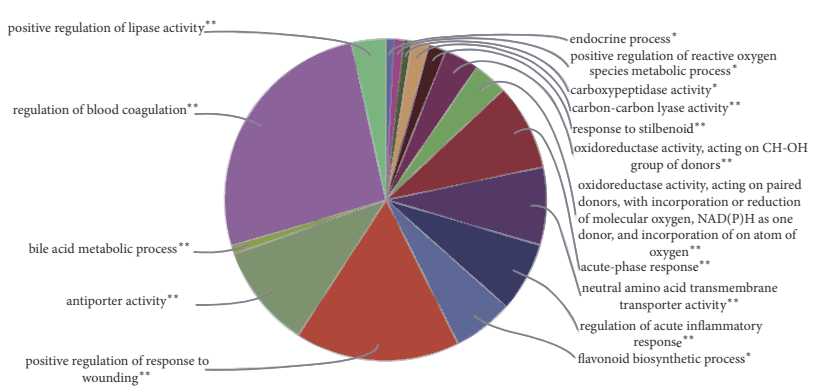

(c)

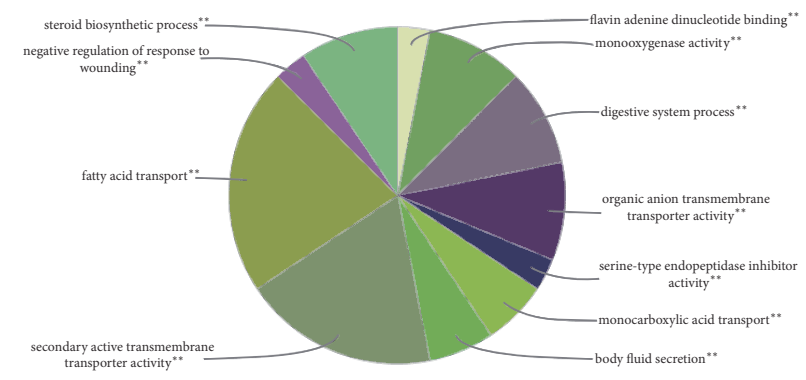

(d)

FIGURE 3: Functionally grouped network of enriched GO categories generated for the upregulated and downregulated genes. GO terms are represented as nodes. Functionally related groups partially overlap (a). Node pie charts represent the biological process analysis for upregulated genes (b) and downregulated genes (c) and uncertain genes (d). 


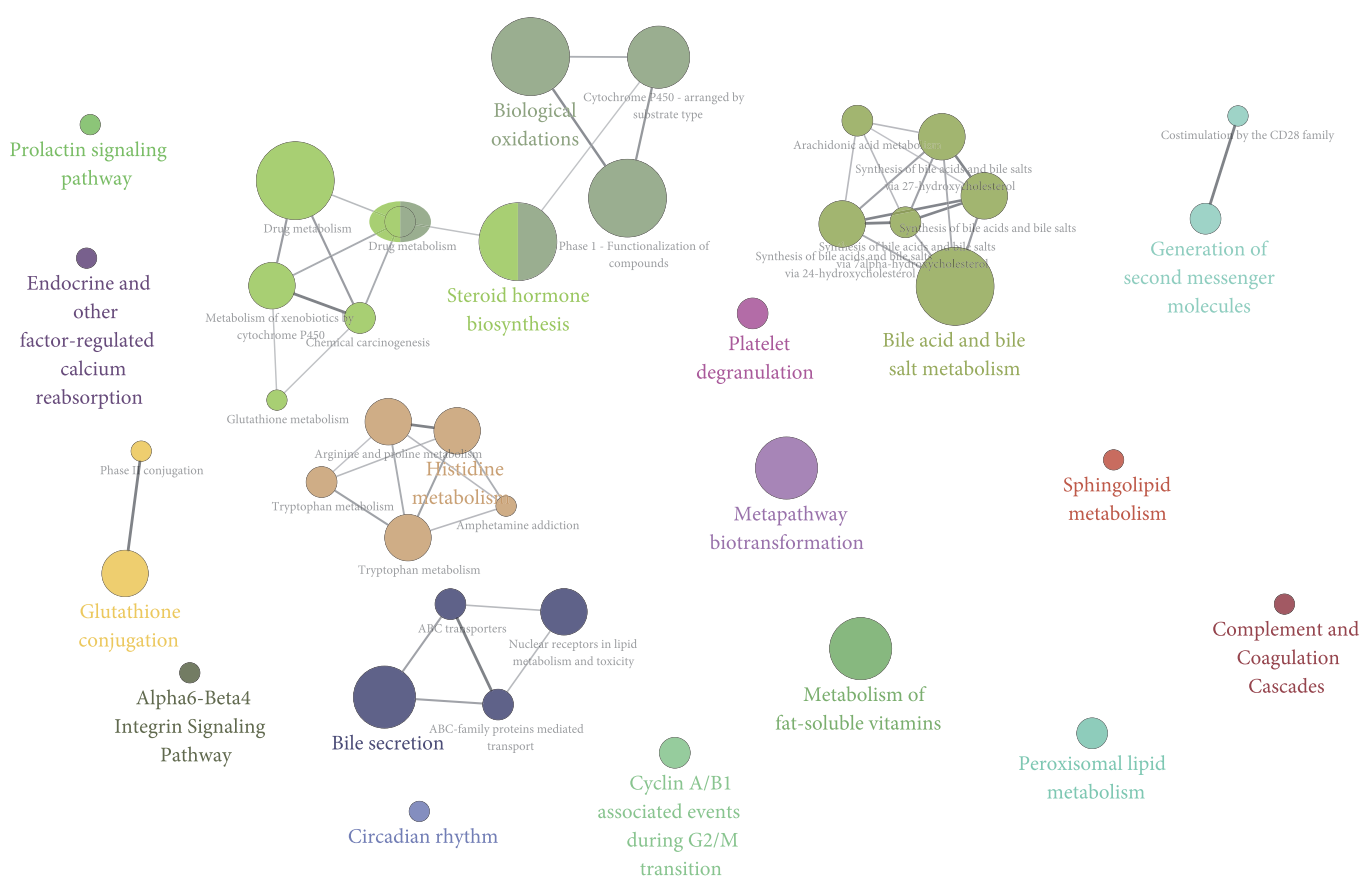

(a)

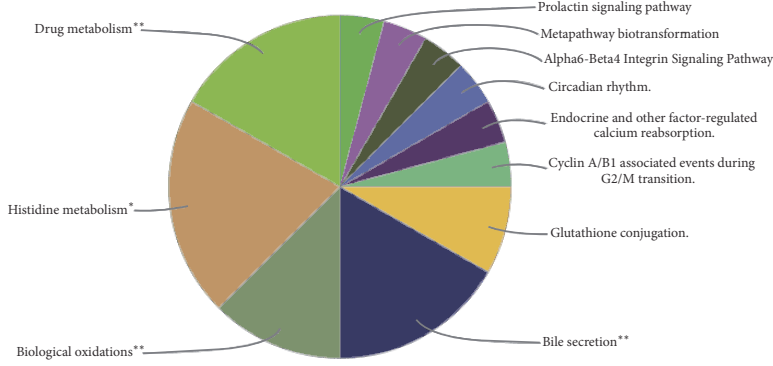

(b)

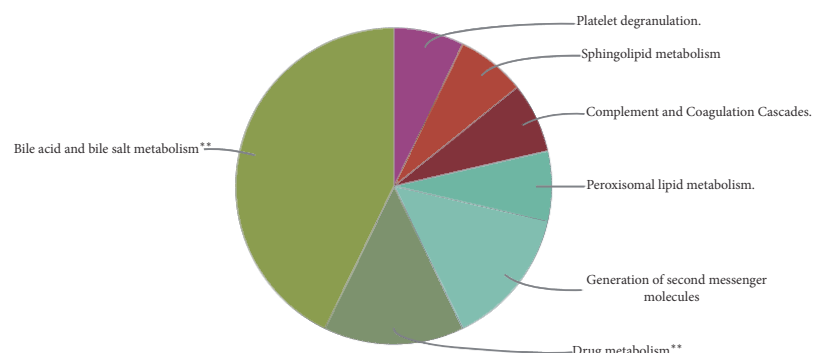

(c)

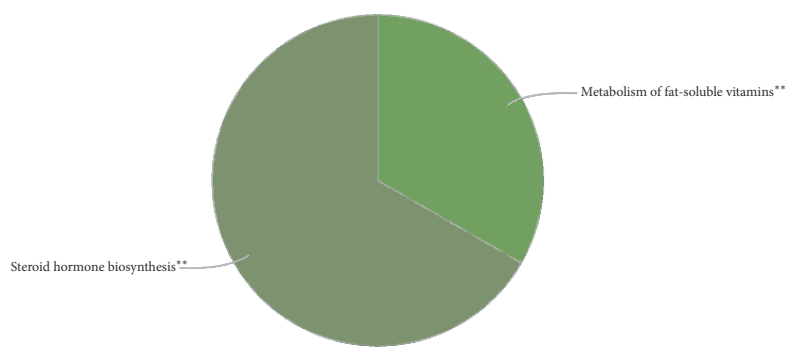

(d)

FIGURE 4: Functionally grouped network of enriched pathway categories was generated for the upregulated and downregulated genes. Pathway terms are represented as nodes. Functionally related groups partially overlap (a). The node pie charts represent pathway analyses for upregulated genes (b) and downregulated genes (c) and uncertain genes (d).

of DN remains highly complex to be fully understood. In this study, cDNA microarray analysis was employed to clarify the underlying mechanism in $\mathrm{db} / \mathrm{db}$ mice, an ideal animal model for type $2 \mathrm{DN}$. A total of 164 downregulated genes and 191 upregulated genes were identified. Enriched significant GO terms and pathways based on these DEGs were also determined. In addition, 10 hub genes were selected from the main PPI network constructed from DEGs according to their $\mathrm{BC}$ and degree.
In this study, biological oxidation was determined to be the most significant pathway, which includes the upregulation of Aoc1, BC021614, Cyp17a1, Cyp27b1, Cyp2d22, Cyp2d26, Cyp4a14, Ephx1, Gm10639, Gm3776, Gsto1, Maoa, and Maob and downregulation of Ces2c, Cndp2, Cyp2a4, Cyp51, and Cyp7b1. Meanwhile, Cyp17a1, Cyp27b1, Cyp2d22, Cyp2d26, Cyp4a14 Cyp2a4, Cyp51, and Cyp7b1 are members of the CYP450 superfamily, which is highly implicated in sustaining the redox balance and limiting the source of oxidative 
TABLE 2: Top 10 enriched GO terms for DEGs sorted by $p$ value (ascending).

\begin{tabular}{|c|c|c|c|c|}
\hline GOID & GO term & $\begin{array}{l}\text { Term } p \text { value } \\
\text { corrected with } \\
\text { Bonferroni step } \\
\text { down } \\
\end{array}$ & Genes cluster \#1 & Genes cluster \#2 \\
\hline GO:0030193 & $\begin{array}{l}\text { Regulation of blood } \\
\text { coagulation }\end{array}$ & $7.10 E-07$ & [Apoe, Ptger3, Serpine2] & $\begin{array}{c}\text { [Apoh, Cd209a, Cd36, Hrg, Proc, } \\
\text { Rpl3, Serpinf2, Tc2n] }\end{array}$ \\
\hline GO:0015291 & $\begin{array}{c}\text { Secondary active } \\
\text { transmembrane transporter } \\
\text { activity }\end{array}$ & $1.00 E-06$ & $\begin{array}{c}{[G m 6614, \text { Slc22a29, Slc5a1, }} \\
\text { Slc6a12, Slc7a12, Slc8a1, Slco4a1] }\end{array}$ & $\begin{array}{c}{[M f s d 2 a, \text { Slcla4, Slc22a19, }} \\
\text { Slc22a26, Slc22a28, Slc6a9, } \\
\text { Slc7a13, Slc9a8, Slco1a1, Tmco3] }\end{array}$ \\
\hline GO:0008514 & $\begin{array}{l}\text { Organic anion } \\
\text { transmembrane transporter } \\
\text { activity }\end{array}$ & $3.30 E-06$ & $\begin{array}{c}\text { [Abcc4, Gm6614, Slc22a29, } \\
\text { Slc6a12, Slc7a12, Slco4a1] }\end{array}$ & $\begin{array}{c}\text { [Slc1a4, Slc22a19, Slc22a26, } \\
\text { Slc22a28, Slc22a7, Slc6a9, } \\
\text { Slc7a13, Slco1a1] }\end{array}$ \\
\hline GO:0019216 & $\begin{array}{l}\text { Regulation of lipid } \\
\text { metabolic process }\end{array}$ & $1.90 E-05$ & $\begin{array}{c}\text { [Abhd6, Angptl3, Angptl8, Apoc1, } \\
\text { Apoe, C3, Cyp17a1, Cyp27b1, } \\
\text { Fabp1, Pdk1, Pik3r3, Proxl] }\end{array}$ & $\begin{array}{c}\text { [Akrlc18, Apoh, Esrl, Kcnmal, } \\
\text { Nt5e] }\end{array}$ \\
\hline GO:0004497 & Monooxygenase activity & $3.10 E-05$ & $\begin{array}{c}\text { [Agmo, Cyp17a1, Cyp27b1, } \\
\text { Cyp2d22, Cyp2d26, Cyp4a14] }\end{array}$ & $\begin{array}{c}\text { [Akr1c18, Cyp2a4, Cyp2j13, Cyp51, } \\
\text { Cyp7b1, Fmo5] }\end{array}$ \\
\hline GO:0015297 & Antiporter activity & $1.00 E-04$ & [Slc22a29, Slc7a12, Slc8a1] & $\begin{array}{c}{[\text { Slc22a19, Slc22a26, Slc22a28, }} \\
\text { Slc7a13, Slc9a8, Tmco3] }\end{array}$ \\
\hline GO:0009636 & Response to toxic substance & $1.40 E-04$ & $\begin{array}{c}\text { [Aocl, Apoe, Cyp17al, Ephxl, } \\
\text { Fabpl, Gria3, Gsta4, Gstol, Ltc4s, } \\
\text { Maob, Nupr1] }\end{array}$ & [Bdh1, Ccl5, Cd36, Ubiad1] \\
\hline GO:0015908 & Fatty acid transport & $1.80 E-03$ & [Abcc4, Apoe, Fabp1] & [Ace, Cd36, Crot, Mfsd2a] \\
\hline GO:0016765 & $\begin{array}{c}\text { Transferase activity, } \\
\text { transferring alkyl or aryl } \\
\text { (other than methyl) groups }\end{array}$ & $1.80 E-03$ & $\begin{array}{c}\text { [BC021614, Gm10639, Gsta4, } \\
\text { Gsto1, Ltc4s] }\end{array}$ & [Agps, Ubiad1] \\
\hline GO:0022600 & Digestive system process & $1.90 E-03$ & [Cyp27b1, Fabp1, Ptger3, Slc5a1] & [Cckar, Cd36, Chrm3, Kcnmal] \\
\hline
\end{tabular}

TABLE 3: Top 10 enriched pathway terms of DEGs sorted by $p$ value (ascending).

\begin{tabular}{|c|c|c|c|c|}
\hline GO term & Ontology source & $\begin{array}{c}\text { Term } p \text { value } \\
\text { corrected with } \\
\text { Bonferroni step } \\
\text { down } \\
\end{array}$ & Genes cluster \#1 & Genes cluster \#2 \\
\hline Biological oxidations & REACTOME_10.02.2016 & $520.0 E-9$ & $\begin{array}{c}\text { [Aoc1, BC021614, Cyp17a1, } \\
\text { Cyp27b1, Cyp2d22, Cyp2d26, } \\
\text { Cyp4a14, Ephx1, Gm10639, } \\
\text { Gm3776, Gstol, Maoa, Maob] }\end{array}$ & $\begin{array}{c}\text { [Ces2c, Cndp2, Cyp2a4, } \\
\text { Cyp51, Cyp7b1] }\end{array}$ \\
\hline $\begin{array}{l}\text { Bile acid and bile salt } \\
\text { metabolism }\end{array}$ & REACTOME_10.02.2016 & $120.0 E-6$ & {$[A b c c 3, G m 6614]$} & $\begin{array}{c}\text { [Akrlc14, Akr1c18, Amacr, } \\
\text { Cyp7b1, Slcola1] }\end{array}$ \\
\hline $\begin{array}{l}\text { Steroid hormone } \\
\text { biosynthesis }\end{array}$ & KEGG_10.02.2016 & $440.0 E-6$ & $\begin{array}{c}\text { [Cyp17a1, Cyp2d22, Cyp2d26, } \\
\text { Ugt2b34] }\end{array}$ & $\begin{array}{c}{[A k r 1 c 18, C y p 7 b 1, H s d 17 b 2,} \\
\text { Ugt2b37, Ugt2b38] }\end{array}$ \\
\hline Bile secretion & KEGG_10.02.2016 & $680.0 E-6$ & $\begin{array}{c}{[A b c b 1 a, A b c b 1 b, A b c c 3, A b c c 4} \\
E p h x 1, S l c 5 a 1]\end{array}$ & [Slc22a7, Slco1a1] \\
\hline $\begin{array}{l}\text { Metabolism of fat-soluble } \\
\text { vitamins }\end{array}$ & REACTOME_10.02.2016 & $770.0 E-6$ & [Apoe, Cyp27b1, Gc, Ttr] & [Akrlc14, Akr1c18, Ubiad1] \\
\hline $\begin{array}{l}\text { Metapathway } \\
\text { biotransformation }\end{array}$ & WikiPathways_10.02.2016 & $3.5 E-3$ & $\begin{array}{c}\text { [Cyp17a1, Cyp27b1, Ephx1, } \\
\text { Gm3776, Gsta4, Gsto1] }\end{array}$ & $\begin{array}{c}\text { [Chst11, Cyp51, Cyp7b1, } \\
\text { Fmo5] }\end{array}$ \\
\hline Glutathione conjugation & REACTOME_10.02.2016 & $6.2 E-3$ & $\begin{array}{c}\text { [BC021614, Gm10639, Gm3776, } \\
\text { Gsto1] }\end{array}$ & [Cndp2] \\
\hline $\begin{array}{l}\text { Generation of second } \\
\text { messenger molecules }\end{array}$ & REACTOME_10.02.2016 & $93.0 E-3$ & & [Cd3e, Cd3g, Grap2] \\
\hline $\begin{array}{l}\text { Peroxisomal lipid } \\
\text { metabolism }\end{array}$ & REACTOME_10.02.2016 & $93.0 E-3$ & & [Agps, Amacr, Crot] \\
\hline $\begin{array}{l}\text { Cyclin } \mathrm{A} / \mathrm{B} 1 \text { associated } \\
\text { events during } \mathrm{G} 2 / \mathrm{M} \\
\text { transition }\end{array}$ & REACTOME_10.02.2016 & $93.0 E-3$ & [Ccnb2, Plk1, Wee1] & \\
\hline
\end{tabular}




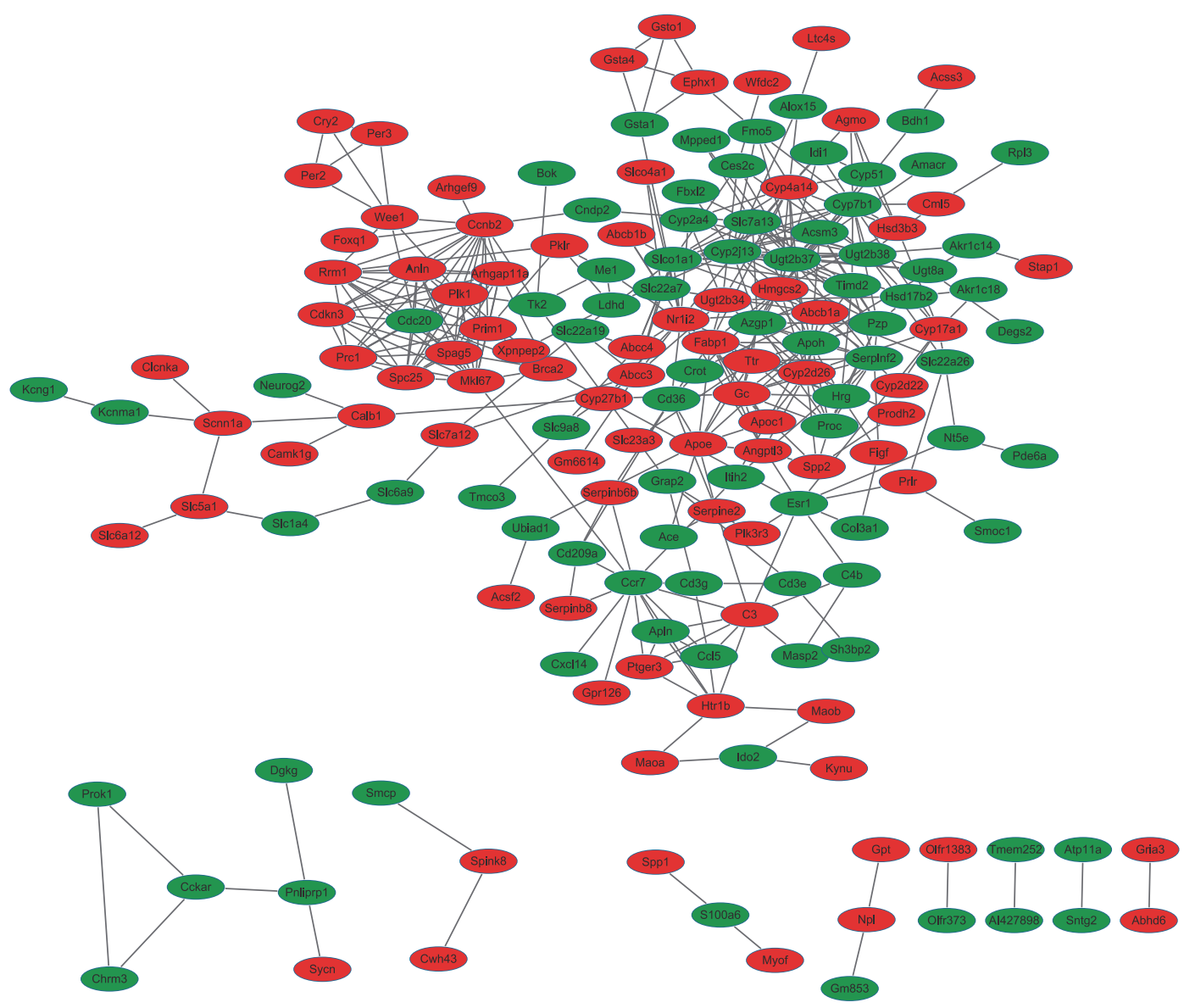

FIGURE 5: Interactome of the 355 genes showing 166 nodes and 411 edges in the protein-protein interaction map encompassing 4 clusters in $\mathrm{DN}$. Genes are denoted as nodes in the graph, and interactions between them are presented as edges. Green indicates downregulated genes, whereas red indicates upregulated genes.

TABLE 4: Top 10 hub genes from PPI network.

\begin{tabular}{lccc}
\hline Name & Betweenness centrality & Degree & Fold change \\
\hline Nrli2 & 0.245983 & 14 & -1.58 \\
Esr1 & 0.22107 & 9 & -1.71 \\
Ccr7 & 0.127205 & 13 & -1.59 \\
C3 & 0.085003 & 9 & -1.58 \\
Slc7a13 & 0.082573 & 14 & -2.23 \\
Slco1a1 & 0.080427 & 16 & -84.31 \\
Apoh & 0.078909 & 17 & -1.84 \\
Ccnb2 & 0.07628 & 15 & 1.6 \\
Cyp2j13 & 0.067509 & 17 & -1.94 \\
Fabp1 & 0.066322 & 12 & 1.62 \\
Ugt2b37 & 0.065938 & 20 & -4.4 \\
\hline
\end{tabular}

stress $[9,10]$. Park et al. reported abnormal expression of multiple CYP450 isoforms in Zucker diabetic rats, indicating that high glucose maybe result to the disorder of CYP450 families [11]. Both monoamine oxidases A and B are flavin adenine dinucleotide-dependent enzymes. Deamination of noradrenaline, serotonin, and dopamine leads to the production of hydrogen peroxide ( $\mathrm{H} 2 \mathrm{O} 2)$. MAO activity as a source of reactive oxygen (ROS) has recently been investigated [12], and hyperglycemia led to increased MAO-A expression and overproduction of ROS in diabetic rats [13]. Thus, the DEGs involved in biological oxidation may be participants in the pathogenesis of $\mathrm{DN}$ via oxidative stress.

An increasing number of studies have recently indicated that hormonal imbalance participated in the development of $\mathrm{DN}$ [14-16]. In the present study, steroid hormone analyses from the KEGG database were found to be significant in the enrichment analysis, which involves the upregulation of Cyp17a1, Cyp2d22, Cyp2d26, and Ugt2b34 and downregulation of Akr1c18, Cyp7b1, Hsd17b2, Ugt2b37, and Ugt2b38. HSD17B2 converts testosterone, dihydrotestosterone (DHT), and estradiol into their cognate inactive metabolites, Adione, $5 \alpha \mathrm{A}$-dione, and estrone, respectively. Cyp2d22 and Cyp2d26, a homolog of human Cyp2d6, exhibited a modest catalyzed activity from estradiol to $2-\mathrm{OH}-\mathrm{E} 2$ and $2-\mathrm{OH}-$ E1 [17]. Cyp7b1 metabolizes $5 \alpha$-androstane- $3 \beta, 17 \beta$-diol ( $3 \beta$ Adiol) and dehydroepiandrosterone. Ugt $2 b 15$, an ortholog of Ugt2b38, catalyzes the conjugation of the $17 \beta$-hydroxy position of DHT, testosterone, and $3 \alpha$-Diol [18]. Dysregulation of these genes led to reduced estrogen and elevated androgen levels. The close association between plasma leptin concentration and sex hormones has been demonstrated by Thomas et al. [19], while excess of circulating leptin may 


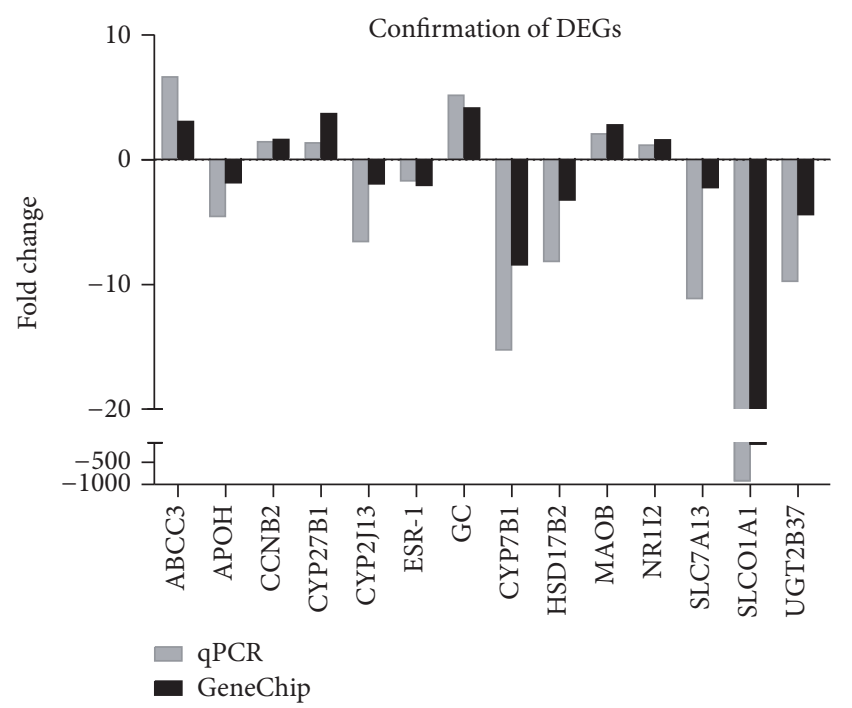

Figure 6: Confirmation of 14 representative DEGs by qPCR. The alterations in these genes at the mRNA level are similar between qPCR and GeneChip.

be an important contributor to the development of reduced androgens in male obesity [20]. These may partly account for the disorder of sex hormones regulated genes in leptin signaling deficient $\mathrm{db} / \mathrm{db}$ mice. Estradiol administration to $\mathrm{db} / \mathrm{db}$ mice improved $\mathrm{DN}$ [21]. Consistent with this finding, Esr-1 encoded a receptor of estradiol, which is involved in DN [22], that was also significantly reduced in the current study.

We found that bile acid synthesis disorder may be associated with the pathogenesis of DN. This disorder includes bile acid and bile salt metabolism based on the reactome pathway, bile secretion from the KEGG pathway, and bile acid metabolic process from GO terms. Abcc3 encodes MRP3, and $A b c c 4$ encodes MRP4. Both transport the taurine and glycine conjugates of bile acids, as well as the unconjugated bile acid cholate, into blood. Slcolal encodes OATP1A1, which can transport unconjugated and conjugated bile acids into cells [23]. Decreased Slcola1 and increased Abcc3 and Abcc4 that were found in the present study would lead to loss of conjugated and unconjugated bile acid and bile salts in the cell. This finding is consistent with those in a previous study [24]. Cholic acid has been reported to alleviate kidney damage in $\mathrm{db} / \mathrm{db}$ mice via modulation of renal lipid metabolism and modulation of fibrosis and inflammation [25]. The study from Liang and Tall suggested that supplement with leptin reversed the deficiency in bile acid synthesis and transport as well as lipoprotein and energy metabolism in ob/ob mice, indicating the important role of leptin in regulating bile acid metabolism [26]. Elevated bile acid pool in STZ-induced diabetic mice and spontaneous diabetic ob/ob mice also revealed that high glucose is an important regulator of bile acid synthesis [27]. FXR is a major receptor of bile acid. Its deficiency-exacerbated diabetic nephropathy occurred in type 1 diabetic rats [28]. In addition, OATP1A2 can also transport dehydroepiandrosterone sulfate, a precursor for the synthesis of steroid hormones [29]. The serum level of dehydroepiandrosterone sulfate was negatively correlated with severe diabetic nephropathy [30].

In addition to identifying the pathway involved in $\mathrm{DN}$, we also distinguished 10 hub genes based on the PPI network from DEGs, some of which were not reported in DN. Notably, Nrli2 encodes the pregnane $\mathrm{X}$ receptor, a nuclear receptor. However, no direct evidence of PXR involvement in DN is available. On the one hand, PXR may play a more important role in regulating the metabolism of drugs being used to treat DN because of its general role in controlling drug responses [31]. On the other hand, PXR influences macrophage sensitivity to cholesterol. Abnormal lipid metabolism in the kidney has been implicated in the development of DN. The current study found elevated PXR in $\mathrm{db} / \mathrm{db}$ mice, suggesting that PXR regulates lipid metabolism and drug response in $\mathrm{DN}$.

Cyclin B2 encoded by Ccnb2 is a member of the cyclin family, specifically the B-type cyclins. Cyclin B2 is associated with p34cdc2 and is an essential component of the cell cycle regulatory machinery. Cyclin B2 is primarily associated with the Golgi region. It also binds to transforming growth factor beta R2. Thus, cyclin B2/cdc2 may play a key role in transforming growth factor beta-mediated cell cycle control. Ccnb2 increased in podocytes in rats with experimental membranous nephropathy. Increased Ccnb2 expression promotes the proliferation of the cell, which may be associated with the proliferation of mesangial and tubular cells in high glucose, along with elevated TGF- $\beta 1$ expression. In the present study, $\mathrm{db} / \mathrm{db}$ mice exhibited upregulation of Ccnb2 at the mRNA level, suggesting its contribution to DN via interference with cell G2/M phage.

Cyp2j13 is an ortholog of Cyp2j2 in humans, which is mainly expressed in the kidneys of mice. Cyp2j13 is responsible for the conversion of arachidonic acid to EETs via the epoxygenase pathway [32]. Several reports suggested that EET production was significantly decreased in the kidney of STZ-induced diabetic rats and high glucose-treated proximal tubular epithelial cells [33-35]. Inhibition of EETs results in overproduction, cellular hypertrophy, and accumulation of fibronectin and collagen IV in high glucose incubated tubular cells [34]. Furthermore, overexpression of endothelial Cyp2j2 also attenuated renal injuries in diabetic rats [36]. Cyp2j13 was reduced in the study, suggesting its involvement in DN by decreasing EET production.

Cyp27b1 encodes a member of the cytochrome P450 superfamily of enzymes, the enzyme that catalyzes the conversion of 25-hydroxyvitamin $\mathrm{D} 3(25(\mathrm{OH}) \mathrm{D})$ to 1-alpha,25dihydroxyvitamin D3 $(1,25(\mathrm{OH}) 2 \mathrm{D})$, the active form of vitamin $\mathrm{D} 3$. It then binds to the vitamin $\mathrm{D}$ receptor and regulates calcium metabolism. Thus, this enzyme plays an important role in normal bone growth, calcium metabolism, and tissue differentiation via regulation of biologically active vitamin D. Cyp27b1 mRNA expression, which was increased in the kidney from diabetic DBA mice, revealed dysregulation of the vitamin $\mathrm{D}$ endocytic pathway $[37,38]$. The current study supports that Cyp27b1 could be participants in the development of DN via regulation of vitamin D signaling.

Apoh encodes $\beta 2 \mathrm{GPI}$, a $54.2 \mathrm{kDa}$ single-chain protein containing four N-linked glycosylation sites, which is essential for binding phospholipids. Apoh also binds to various 
kinds of negatively charged substances such as heparin, phospholipids, and dextran sulfate. It plays multiple roles in coagulation and fibrinolytic pathways, placental homeostasis, athermanous plaque formation, endothelial cell activation, and apoptotic mechanisms [39]. The transcriptome analysis from human DN revealed the downregulation of Apoh in the diabetic tubule [5]. Increased urinary $\beta 2$ GPI excretion was proven to be a biomarker of impaired tubular reabsorption of protein in diabetics without clinical proteinuria [40]. Contradictory to these findings, reduced $\beta 2 \mathrm{GPI}$ ameliorated renal morphometric damage and kidney function in STZinduced diabetic rats via inhibition of the TGF- $\beta 1$-p38 MAPK pathway [41]. The present study revealed reduced expression of Apoh. However, the role of Apoh in DN has yet to be elucidated.

\section{Conclusion}

The current findings together indicate that upregulation of 164 probesets with genes and downregulation of 191 probesets. The DEGs were enriched for biological oxidation, steroid hormone biosynthesis, and bile acid metabolism. Some recognized hub genes, such as Ccnb2, Nrli2 and others, provide new insights into the molecular pathogenesis of $\mathrm{DN}$.

\section{Competing Interests}

The authors have no conflict of interests.

\section{Acknowledgments}

This work was supported by a Project of International Collaboration in Science and Technology Grant, China (Grant no. 2011DFA31860) and the National Natural Science Foundation of China (Grants nos. 81173422, 81373795, 81302942, and 81473526).

\section{References}

[1] H. Nasri, "On the occasion of the world diabetes day 2013; Diabetes education and prevention; a nephrology point of view," Journal of Renal Injury Prevention, vol. 2, no. 2, pp. 31-32, 2013.

[2] S. B. Ghaderian, F. Hayati, S. Shayanpour, and S. S. Beladi Mousavi, "Diabetes and end-stage renal disease; a review article on new concepts," Journal of Renal Injury Prevention, vol. 4, no. 2, pp. 28-33, 2015.

[3] M. Pourghasem, H. Shafi, and Z. Babazadeh, "Histological changes of kidney in diabetic nephropathy," Caspian Journal of Internal Medicine, vol. 6, no. 3, pp. 120-127, 2015.

[4] S. C. Tang, G. C. Chan, and K. N. Lai, "Recent advances in managing and understanding diabetic nephropathy," F1000Research, vol. 5, article no. 1044, 2016.

[5] K. I. Woroniecka, A. S. D. Park, D. Mohtat, D. B. Thomas, J. M. Pullman, and K. Susztak, "Transcriptome analysis of human diabetic kidney disease," Diabetes, vol. 60, no. 9, pp. 2354-2369, 2011.

[6] H. Schmid, A. Boucherot, Y. Yasuda et al., "Modular activation of nuclear factor- $\kappa \mathrm{B}$ transcriptional programs in human diabetic nephropathy," Diabetes, vol. 55, no. 11, pp. 2993-3003, 2006.

[7] T. Watanabe, N. H. Tomioka, M. Doshi, S. Watanabe, M. Tsuchiya, and M. Hosoyamada, "Macrophage migration inhibitory factor is a possible candidate for the induction of microalbuminuria in diabetic $\mathrm{db} / \mathrm{db}$ mice," Biological \& Pharmaceutical Bulletin, vol. 36, no. 5, pp. 741-747, 2013.

[8] G. H. Tesch and A. K. H. Lim, "Recent insights into diabetic renal injury from the $\mathrm{db} / \mathrm{db}$ mouse model of type 2 diabetic nephropathy," American Journal of Physiology-Renal Physiology, vol. 300, no. 2, pp. F301-F310, 2011.

[9] S. Bhattacharyya, K. Sinha, and P. C. Sil, "Cytochrome P450s: mechanisms and biological implications in drug metabolism and its interaction with oxidative stress," Current Drug Metabolism, vol. 15, no. 7, pp. 719-742, 2014.

[10] E. G. Hrycay and S. M. Bandiera, "Involvement of cytochrome $\mathrm{P} 450$ in reactive oxygen species formation and cancer," Advances in Pharmacology, vol. 74, pp. 35-84, 2015.

[11] S. Y. Park, C. H. Kim, J. Y. Lee et al., "Hepatic expression of cytochrome P450 in Zucker diabetic fatty rats," Food and Chemical Toxicology, vol. 96, pp. 244-253, 2016.

[12] M. E. Manni, E. Bigagli, M. Lodovici, M. Zazzeri, and L. Raimondi, "The protective effect of losartan in the nephropathy of the diabetic rat includes the control of monoamine oxidase type A activity," Pharmacological Research, vol. 65, no. 4, pp. 465-471, 2012.

[13] P. Umbarkar, S. Singh, S. Arkat, S. L. Bodhankar, S. Lohidasan, and S. L. Sitasawad, "Monoamine oxidase-A is an important source of oxidative stress and promotes cardiac dysfunction, apoptosis, and fibrosis in diabetic cardiomyopathy," Free Radical Biology \& Medicine, vol. 87, pp. 263-273, 2015.

[14] Q. Xu, C. C. Wells, J. H. Garman, L. Asico, C. S. Escano, and C. Maric, "Imbalance in sex hormone levels exacerbates diabetic renal disease," Hypertension, vol. 51, no. 4, pp. 1218-1224, 2008.

[15] T. Costacou, L. Fried, D. Ellis, and T. J. Orchard, "Sex differences in the development of kidney disease in individuals with type 1 diabetes mellitus: a contemporary analysis," American Journal of Kidney Diseases, vol. 58, no. 4, pp. 565-573, 2011.

[16] C. Maric, "Sex, diabetes and the kidney," American Journal of Physiology-Renal Physiology, vol. 296, no. 4, pp. F680-F688, 2009.

[17] A. J. Lee, M. X. Cai, P. E. Thomas, A. H. Conney, and B. T. Zhu, "Characterization of the oxidative metabolites of $17 \beta$ estradiol and estrone formed by 15 selectively expressed human cytochrome P450 isoforms," Endocrinology, vol. 144, no. 8, pp. 3382-3398, 2003.

[18] D. Turgeon, J.-S. Carrier, E. Lévesque, D. W. Hum, and A. Bélanger, "Relative enzymatic activity, protein stability, and tissue distribution of human steroid-metabolizing UGT2B subfamily members," Endocrinology, vol. 142, no. 2, pp. 778-787, 2001.

[19] T. Thomas, B. Burguera, L. J. Melton III et al., "Relationship of serum leptin levels with body composition and sex steroid and insulin levels in men and women," Metabolism: Clinical and Experimental, vol. 49, no. 10, pp. 1278-1284, 2000.

[20] A. M. Isidori, M. Caprio, F. Strollo et al., "Leptin and androgens in male obesity: evidence for leptin contribution to reduced androgen levels," The Journal of Clinical Endocrinology and Metabolism, vol. 84, no. 10, pp. 3673-3680, 1999.

[21] M. Chin, M. Isono, K. Isshiki et al., "Estrogen and raloxifene, a selective estrogen receptor modulator, ameliorate renal damage 
in db/db mice," American Journal of Pathology, vol. 166, no. 6, pp. 1629-1636, 2005.

[22] A. Inada, O. Inada, N. L. Fujii et al., "Adjusting the $17 \beta$-estradiolto-androgen ratio ameliorates diabetic nephropathy," Journal of the American Society of Nephrology, vol. 27, no. 10, pp. 30353050, 2016.

[23] G. A. Kullak-Ublick, B. Hagenbuch, B. Stieger et al., "Molecular and functional characterization of an organic anion transporting polypeptide cloned from human liver," Gastroenterology, vol. 109, no. 4, pp. 1274-1282, 1995.

[24] V. R. More, X. Wen, P. E. Thomas, L. M. Aleksunes, and A. L. Slitt, "Severe diabetes and leptin resistance cause differential hepatic and renal transporter expression in mice," Comparative Hepatology, vol. 11, no. 1, article 1, 2012.

[25] T. Jiang, X. X. Wang, P. Scherzer et al., "Farnesoid X receptor modulates renal lipid metabolism, fibrosis, and diabetic nephropathy," Diabetes, vol. 56, no. 10, pp. 2485-2493, 2007.

[26] C.-P. Liang and A. R. Tall, "transcriptional profiling reveals global defects in energy metabolism, lipoprotein, and bile acid synthesis and transport with reversal by leptin treatment in ob/ob mouse liver," Journal of Biological Chemistry, vol. 276, no. 52, pp. 49066-49076, 2001.

[27] T. Li, J. M. Francl, S. Boehme et al., "Glucose and insulin induction of bile acid synthesis: mechanisms and implication in diabetes and obesity," The Journal of Biological Chemistry, vol. 287, no. 3, pp. 1861-1873, 2012.

[28] X. X. Wang, T. Jiang, Y. Shen et al., "Diabetic nephropathy is accelerated by farnesoid $\mathrm{X}$ receptor deficiency and inhibited by farnesoid X receptor activation in a type 1 diabetes model," Diabetes, vol. 59, no. 11, pp. 2916-2927, 2010.

[29] G.-A. Kullak-Ublick, T. Fisch, M. Oswald et al., "Dehydroepiandrosterone sulfate (DHEAS): identification of a carrier protein in human liver and brain," FEBS Letters, vol. 424, no. 3, pp. 173-176, 1998.

[30] M. Kanauchi, M. Nakajima, and K. Dohi, "Dehydroepiandrosterone sulfate and estradiol in men with diabetic nephropathy [2]," Nephron, vol. 88, no. 1, pp. 95-96, 2001.

[31] C. Zhou, N. King, K. Y. Chen, and J. L. Breslow, "Activation of PXR induces hypercholesterolemia in wild-type and accelerates atherosclerosis in apoE deficient mice," Journal of Lipid Research, vol. 50, no. 10, pp. 2004-2013, 2009.

[32] J. A. Wray, M. C. Sugden, D. C. Zeldin et al., “The epoxygenases CYP2J2 activates the nuclear receptor PPAR $\alpha$ in vitro and in vivo," PLoS ONE, vol. 4, no. 10, Article ID e7421, 2009.

[33] P. Luo, Y. Zhou, H.-H. Chang et al., "Glomerular 20-HETE, EETs, and TGF- $\beta 1$ in diabetic nephropathy," American Journal of Physiology_Renal Physiology, vol. 296, no. 3, pp. F556-F563, 2009.

[34] S. Eid, R. Maalouf, A. A. Jaffa et al., "20-HETE and EETs in diabetic nephropathy: a novel mechanistic pathway," PLoS ONE, vol. 8, no. 8, Article ID e70029, 2013.

[35] H. Shapiro, M. Theilla, J. Attal-Singer, and P. Singer, "Effects of polyunsaturated fatty acid consumption in diabetic nephropathy," Nature Reviews Nephrology, vol. 7, no. 2, pp. 110-121, 2011.

[36] G. Chen, P. Wang, G. Zhao et al., "Cytochrome P450 epoxygenase CYP2J2 attenuates nephropathy in streptozotocin-induced diabetic mice," Prostaglandins \& Other Lipid Mediators, vol. 96, no. 1-4, pp. 63-71, 2011.

[37] F. Pei, B.-Y. Li, Z. Zhang et al., "Beneficial effects of phlorizin on diabetic nephropathy in diabetic $\mathrm{db} / \mathrm{db}$ mice," Journal of Diabetes and Its Complications, vol. 28, no. 5, pp. 596-603, 2014.
[38] Y. Wang, J. Zhou, A. W. Minto et al., "Altered vitamin D metabolism in type II diabetic mouse glomeruli may provide protection from diabetic nephropathy," Kidney International, vol. 70, no. 5, pp. 882-891, 2006.

[39] S. Miyakis, B. Giannakopoulos, and S. A. Krilis, "Beta 2 glycoprotein I-function in health and disease," Thrombosis Research, vol. 114, no. 5-6, pp. 335-346, 2004.

[40] M. Lapsley, F. V. Flynn, and P. A. Sansom, “ $\beta 2$-glycoprotein1 (apolipoprotein $\mathrm{H}$ ) excretion and renal tubular malfunction in diabetic patients without clinical proteinuria," Journal of Clinical Pathology, vol. 46, no. 5, pp. 465-469, 1993.

[41] T. Wang, S.-S. Chen, R. Chen, D.-M. Yu, and P. Yu, "Reduced beta 2 glycoprotein i improve diabetic nephropathy via inhibiting TGF- $\beta 1$-p38 MAPK pathway," International Journal of Clinical and Experimental Medicine, vol. 8, no. 5, pp. 6852-6865, 2015. 


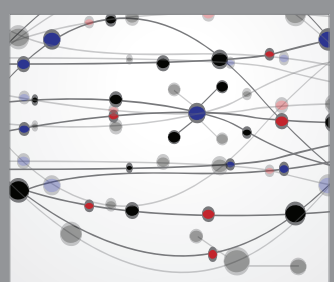

The Scientific World Journal
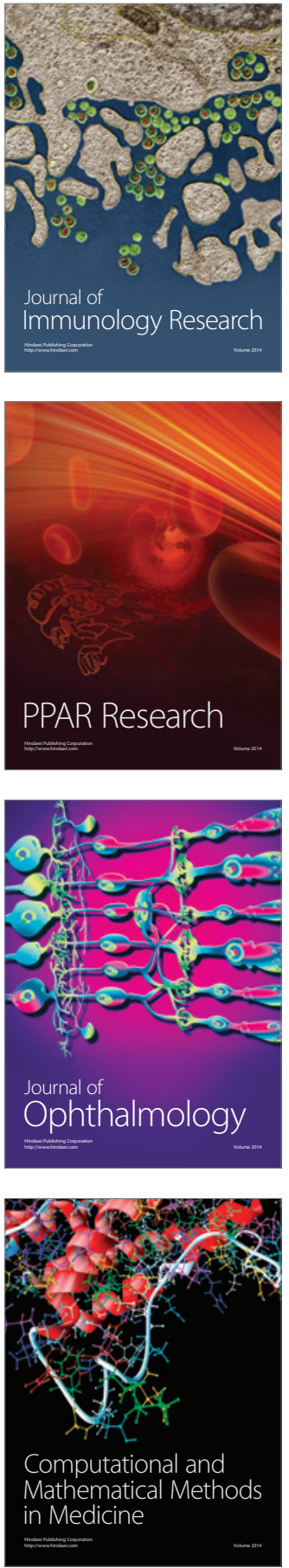

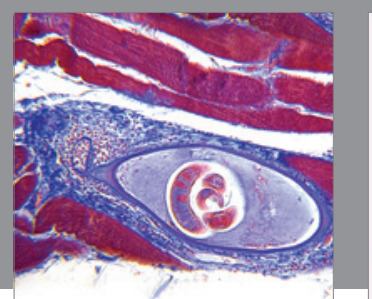

Gastroenterology Research and Practice
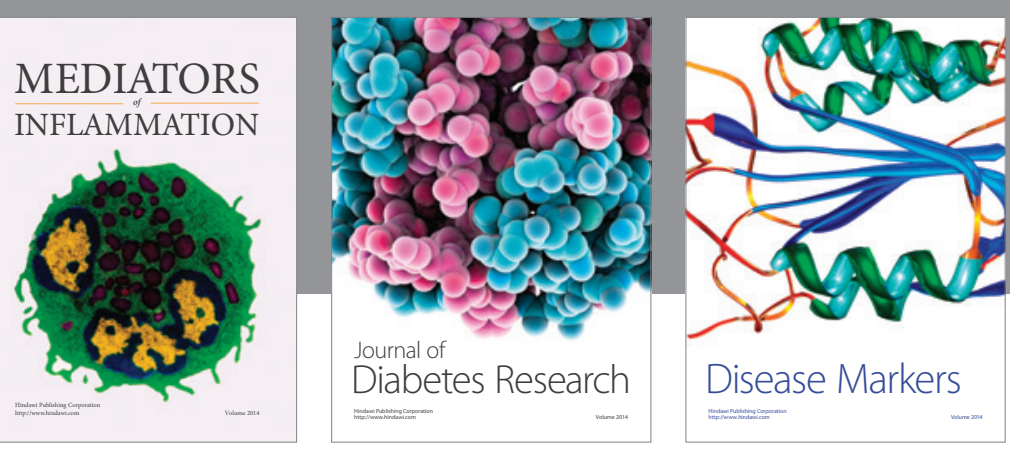

Disease Markers

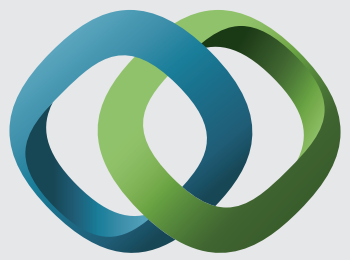

\section{Hindawi}

Submit your manuscripts at

https://www.hindawi.com
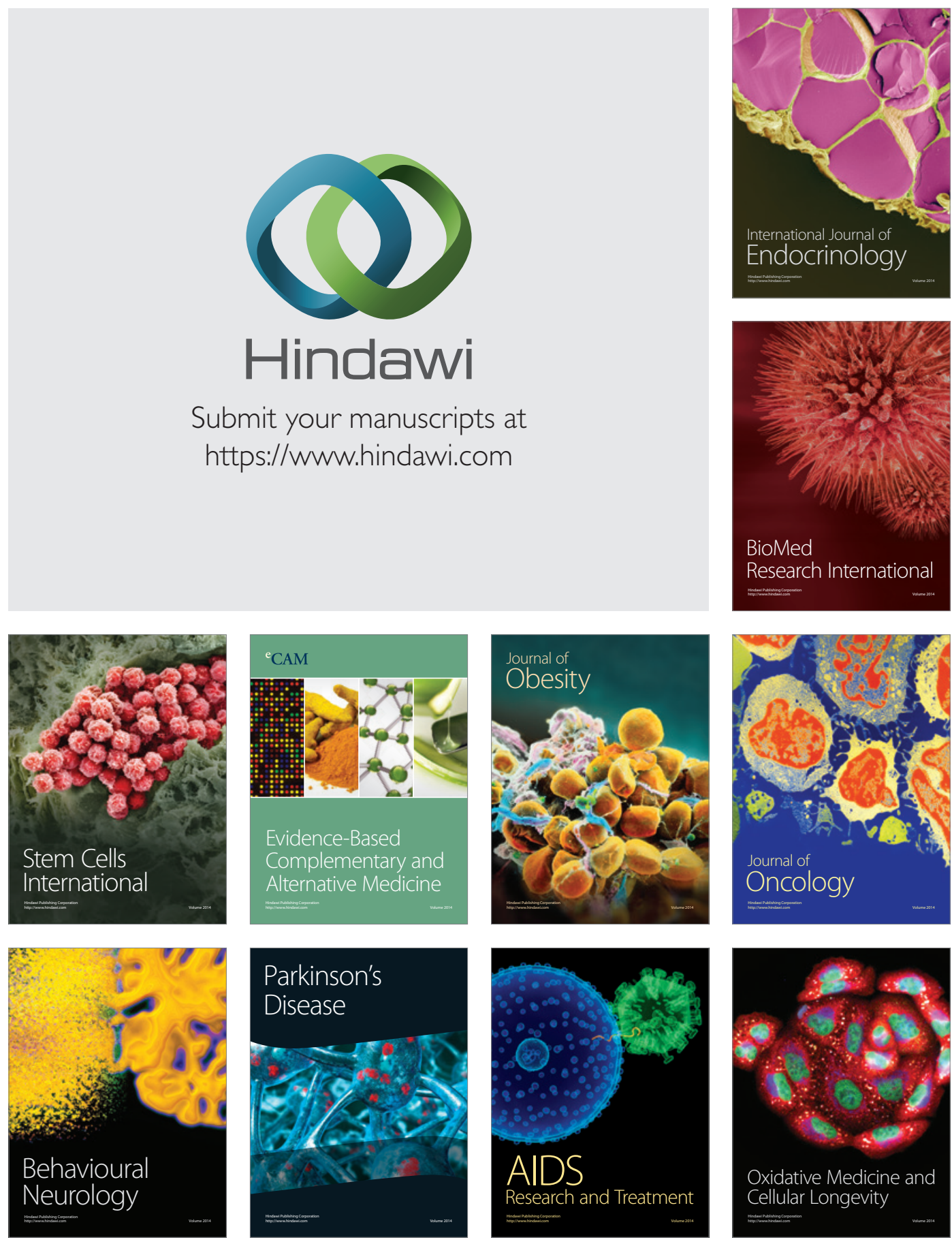